\title{
Lipid Metabolites of Carbon Tetrachloride
}

\author{
ENOCH GoRDIs
}

From The Rockefeller University, New York 10021

\begin{abstract}
A BSTRACT $5 \mathrm{~min}$ after intravenous injection into rats of ${ }^{14} \mathrm{C}$ - or ${ }^{38} \mathrm{Cl}$-carbon tetrachloride, liver lipids were found labeled. Most of the radioactivity was found in the phospholipid fraction. The metabolites were shown to comprise a heterogeneous group of branched longchain chlorinated fatty acids, probably containing the trichloromethyl side chain. Surviving liver slices also formed these metabolites. In a simple chemical system which generates trichloromethyl free radicals, carbon tetrachloride added to methyl oleate to form esters which behaved like the metabolites during countercurrent distribution and urea adduction. The evidence strongly suggests the formation of these metabolites by free radical attack on unsaturated lipids. The relation of these observations to current theories of carbon tetrachloride intoxication is discussed.
\end{abstract}

\section{INTRODUCTION}

Poisoning by carbon tetrachloride has often been thought to result from its ability as a lipid solvent to destroy lipid-rich membranes of cells and subcellular particles. This view is probably incorrect. It fails to explain the variability in toxic dose, the alteration in susceptibility to poisoning produced by antioxidants $(1,2)$, and the greater toxicity of carbon tetrachloride than chloroform (3). Most striking is Slater's demonstration (4) that in equimolar doses, fluorotrichloromethane, a liquid similar to $\mathrm{CCl}_{4}$ in physical properties and solvent power, is not hepatotoxic at all. Other theories of $\mathrm{CCl}_{4}$ poisoning which attribute its effects to the unchanged $\mathrm{CCl}_{4}$ molecule [e.g., stimulation of catechol release (5), interference with blood flow to the centers of liver lobules (6)] are not supported by recent evidence $(7,8)$. Much of this evidence is discussed in Recknagel's comprehensive review (9).

Recent efforts have therefore been concentrated on the relation between the metabolism of $\mathrm{CCl}_{4}$ and its toxicity. In 1951, McCollister, Beamer, Atchison, and Spencer (10) showed that while most ${ }^{14} \mathrm{C}-\mathrm{CCl}_{4}$ breathed by monkeys was exhaled unchanged, a small fraction was

Received for publication 16 July 1968. converted to radioactive carbon dioxide, chloroform, urea, and one or more unidentified urinary organic anions. This group of products did not in itself suggest a toxic mechanism. In 1961, Butler (11) showed that the in vitro reaction of $\mathrm{CCl}_{4}$ with sulfhydryl compounds led to replacement of sulfhydryl hydrogen. He inferred that the reaction mechanism involved the homolytic cleavage of $\mathrm{CCl}_{4}$ into $\mathrm{CCl}_{3} \cdot$ and $\mathrm{Cl} \cdot$ free radicals with radical attack on the susceptible functional groups. In Butler's experiments, sulfhydryl groups were oxidized to disulfide with formation of chloroform. He suggested that in other circumstances, the trichloromethyl radical itself might replace the sulfhydryl hydrogen. Free radical attack on sulfhydryl groups might take place in vivo, but no such products have been identified yet in intoxicated animals. Carbon tetrachloride may poison by means of two other well characterized reactions of free radicals : the addition of halomethanes to olefins (12), and the chain peroxidation of dienes and polyenes (13). In vitro these reactions are best initiated by heat, ultraviolet light, or catalytic amounts of organic peroxides. In the case of addition to olefins, trichloromethyl radicals add to one carbon of the double bond, and depending on the reaction conditions, either $\mathrm{Cl}$ or $\mathrm{H}$ adds to the other. In the case of chain peroxidation of dienes and polyenes, an initiator, which can be the $\mathrm{CCl}_{3} \cdot$ radical, catalyzes the formation of peroxide radicals, but this reaction is selfperpetuating and proceeds without further catalyst. In both cases polymerization can result from one or more couplings of product radicals. Unsaturated lipids are obvious substrates for both free radical reactions.

Reynolds (14) reported that rat liver lipids were labeled after feeding either ${ }^{14} \mathrm{C}$ - or ${ }^{36} \mathrm{C}$-carbon tetrachloride. Microsomal lipids were most heavily labeled. The studies described below demonstrate the labeling of liver lipids within $5 \mathrm{~min}$ after the intravenous injection of ${ }^{14} \mathrm{C}$ - and ${ }^{38} \mathrm{Cl}$-carbon tetrachloride, confirming the observations of Reynolds. The metabolites comprise a heterogeneous group of branched chlorinated long-chain fatty acids. Surviving liver slices also formed these metabolites. These products share the properties of lipids synthesized by benzoyl peroxide-catalyzed addi- 
tion of carbon tetrachloride to unsaturated esters. The structure of the metabolites strongly suggests their formation through attack by trichloromethyl radicals on unsaturated lipids.

\section{METHODS}

Unlabeled carbon tetrachloride, certified ACS grade, was obtained from Fisher Scientific Company, Pittsburgh, Pa., ${ }^{14} \mathrm{C}$-carbon tetrachloride, $7.2 \mathrm{mc} / \mathrm{mm}$, was obtained from Nuclear-Chicago Corporation, Des Plains, Ill., and ${ }^{38} \mathrm{Cl}$ carbon tetrachloride, $0.35 \mathrm{mc} / \mathrm{mm}$, from the Radiochemical Center, Amersham, England. Methyl oleate, $99 \%$ pure, and ampoules of $\mathrm{BF}_{3}$-methanol, were obtained from Applied Science Laboratories, Inc., State College, Pa., and Lipomul fat emulsion for intravenous injection from the Upjohn Co., Kalamazoo, Mich. Silicagel $G$ was purchased from Merck, Darmstadt, Germany, and silicic acid, 100 mesh, A.R., from Mallinckrodt. Liquiflor, a concentrated solution of 2,5-diphenyloxazole (PPO) and 2-p-phenylenebis (5phenyloxazole) (POPOP) in toluene, were obtained from New England Nuclear Corp., Boston, Mass. A 25-fold dilution in toluene provides a solution of PPO $4 \mathrm{~g} /$ liter, and POPOP $50 \mathrm{mg}$ /liter.

Solvents were redistilled before use, unless otherwise noted.

Radioactivities of samples containing ${ }^{14} \mathrm{C}$ or ${ }^{38} \mathrm{Cl}$ were assayed in the double channel Nuclear-Chicago model 720 scintillation counter. Discriminator settings were chosen so that the isotopes could be assayed simultaneously.

Radioactive carbon tetrachloride was administered intravenously to rats without additional unlabeled carbon tetrachloride. The tracer was mixed with Lipomul, yielding a stable aqueous radioactive preparation, since the tracer dissolved in the fat particles of the emulsion. ${ }^{14} \mathrm{C}$-carbon tetrachloride was supplied in a vacuum ampoule. The top of the ampoule was broken under a layer of Lipomul, permitting the radioactive vapor to mix rapidly with the emulsion. ${ }^{38} \mathrm{Cl}$-carbon tetrachloride, of lower specific activity, was supplied as a liquid, and was added to the Lipomul with a Hamilton microsyringe. To assay the radioactivity of the Lipomul- $\mathrm{CCl}_{4}$ mixture, we distributed $5 \mu \mathrm{l}$ in the two phase system, heptane $(4 \mathrm{ml})$-isopropanol $(4 \mathrm{ml})$-water $(3 \mathrm{ml})$, and counted an aliquot of the upper (heptane) phase.

None of the fat in Lipomul was labeled by mixing with carbon tetrachloride. An alternative intravenous preparation, $\mathrm{CCl}_{4}$-propylene glycol-water, yielded identical liver metabolites, but this system incorporated less tracer and introduced a glycol, so that it was abandoned in favor of Lipomul.

To obtain liver lipids, we homogenized livers or liver slices in chloroform-methanol $2: 1(\mathrm{v} / \mathrm{v})$. Homogenates were filtered, the filtrates washed with 0.2 volume of water, and the lipids recovered by evaporating the chloroform and redissolving the residue. "Phospholipids" refers to lipids precipitated in the cold by adding 9 volumes of acetone to a chloroform solution of total lipid extract.

Glyceryl esters were hydrolyzed by refluxing in $4 \mathrm{~N} \mathrm{HCl}$ for $3 \mathrm{hr}$. The reaction mixture was cooled and distributed in about 30 volumes of the two phase system petroleum ether-isopropanol-water $(4: 4: 3 \mathrm{v} / \mathrm{v})$. Fatty acids were recovered from the upper phase by evaporating the solvent in a rotary evaporator. Methyl esters were prepared from the free fatty acids by heating the acids $1 \mathrm{~min}$ at $100^{\circ} \mathrm{C}$ in $\mathrm{BF}_{3}$-methanol. Lipids were not saponified in alkaline alcohols, since these reagents dehalogenate.

Phospholipids were fractionated by chromatography on silicic acid according to the procedure of Hanahan, Dittmer, and Warashina (15). The eluting solvents were evaporated in a rotary evaporator and the residues dissolved in petroleum ether before assay of lipid phosphorus (16) and ${ }^{30} \mathrm{Cl}$ radioactivity.

Countercurrent distributions of fatty acids and of fatty acid methyl esters were performed using the solvent systems of Ahrens and Craig (17). For fatty acids, the solvent phases were prepared by mixing heptane, $97.5 \%$ acetic acid, methanol and acetonitrile $(4: 1: 1: 1 \mathrm{v} / \mathrm{v})$ and allowing phase separation. For methyl esters, the phases were obtained after equilibration of equal volumes of heptane and acetonitrile. Radioactivities were assayed after countercurrent distribution by evaporating an aliquot of each upper phase in a counting vial and redissolving the residue in the scintillation solution.

Branched-chain compounds were distinguished from straight-chain compounds by the formation of urea adducts $(18,19)$. When urea and a straight-chain hydrocarbon are dissolved together in methanol, inclusion complexes precipitate spontaneously. These complexes consist of hollow cylindrical crystals of urea in which the hydrocarbon chain is included. Branching of the chain tends to prevent its inclusion in the urea complex, and branched compounds remain mostly in the supernatant. Fatty acid methyl esters were dissolved in hot $15 \%$ methanolic urea, and the adducts precipitated spontaneously overnight at room temperature. The complexed esters and the excluded esters were recovered separately by distributing the precipitate and the supernatant in the system petroleum ether-methanol-water.

Thin-layer chromatography on Silicagel G impregnated with silver nitrate was used to distinguish saturated from unsaturated esters. Plates $700 \mu$ thick were prepared by a modification of the method of Kaufmann and Wessels (20)

\section{RESULTS}

\section{In vivo studies}

As early as 5 min after intravenous injection of radioactive carbon tetrachloride, rat liver lipids were labeled. The analyses described below were done on lipids obtained $15 \mathrm{~min}$ after injection. Rats were given either ${ }^{30} \mathrm{Cl}$-carbon tetrachloride or "doubly labeled" carbon tetrachloride, a mixture of ${ }^{14} \mathrm{C}$ - and ${ }^{38} \mathrm{Cl}-\mathrm{CCl}_{4}$. The use of carbon tetrachloride labeled only with ${ }^{38} \mathrm{Cl}$ permitted simultaneous comparison of chlorinated metabolites with standard ${ }^{14} \mathrm{C}$-palmitic acid and its methyl ester during countercurrent distribution and urea adduction. Use of doubly labeled $\mathrm{CCl}_{4}$ permitted calculation of the number of chlorine atoms per molecule of $\mathrm{CCl}_{4}$ incorporated into lipid.

\section{Liver Lipids after Injection of ${ }^{30} \mathrm{Cl}$-Carbon TETRACHLORIDE}

Male rats of the Sprague-Dawley strain weighing 125$150 \mathrm{gm}$ were fasted overnight. They were each injected intravenously with $1 \mathrm{ml}$ Lipomul containing $8 \times 10^{5} \mathrm{cpm}$ ${ }^{38} \mathrm{Cl}$-carbon tetrachloride. $15 \mathrm{~min}$ later the rats were decapitated, and the liver lipids were extracted. The lipid extracts contained about $0.5 \%$ of the injected radioactivity. The extracts were pooled, and the phospholipids 
precipitated with acetone. $65 \%$ of the radioactivity was found in the acetone-precipitable lipids. None of the activity in the acetone precipitate was due to ${ }^{36} \mathrm{Cl}$ chloride ion, since shaking a wet solution of the phospholipids with powdered silver carbonate did not reduce the lipid radioactivity.

Distribution of radioactivity in phospholipid fractions. To determine if any class of phospholipid was preferentially labeled, we fractionated a portion of the acetoneprecipitable lipid on a silicic acid column (15). Table I presents the elution sequence, and the lipid phosphorus and ${ }^{38} \mathrm{Cl}$ activity of each fraction. From the finding that all of the phospholipid fractions were labeled, as well as the labeling of acetone-soluble lipids, it appeared probable that the fatty acids were labeled. The remainder of the phospholipid was hydrolyzed, and the fatty acids recovered. To this fatty acid mixture, ${ }^{14} \mathrm{C}$-palmitic acid was added in an amount chosen to make the ${ }^{14} \mathrm{C}$ and ${ }^{38} \mathrm{Cl}$ radioactivities similar. $2 / 3$ of this fatty acid mixture was then esterified in $\mathrm{BF}_{3}$-methanol.

Countercurrent distribution of labeled fatty acids and methyl esters. Phospholipid fatty acids containing ${ }^{36} \mathrm{Cl}$ acids and added ${ }^{14} \mathrm{C}$-palmitic acid were distributed through twenty transfers in the system heptane-acetonitrile-acetic acid-methanol, lower phase $10 \mathrm{ml}$, upper phase $6.8 \mathrm{ml}$. 5-ml aliquots of each upper phase were evaporated in counting vials and the residues dissolved in scintillation fluid for assay of radioactivity. Fig. 1 shows the distribution of the free acids. Fig. 2 shows the distribution of the methyl esters (heptane-acetonitrile, $10 \mathrm{ml}$ upper phase, $10 \mathrm{ml}$ lower phase, $8 \mathrm{ml}$ of upper phases assayed).

The labeled metabolites thus behave as a mixture of long-chain acids. To show that the chlorinated lipid is not a single substance, consider the simultaneous countercurrent distribution of two pure substances, $A$ and $B$, with partition coefficients $K_{a}$ and $K_{b}$. Call the concentration of $A$ in the $r^{\text {th }}$ tube $A r$, and of $B$ in the $r^{\text {th }}$ tube $B$. It can be readily shown that if any two adjacent tubes are compared, say the $r^{\text {th }}$ and the $(r+1)^{\text {th }}$,

TABLE I

${ }^{36} \mathrm{Cl}$-Labelling of Liver Phospholipid Fractions after Administration of ${ }^{36} \mathrm{Cl}$-Carbon Tetrachloride (Silicic Acid Chromatography)

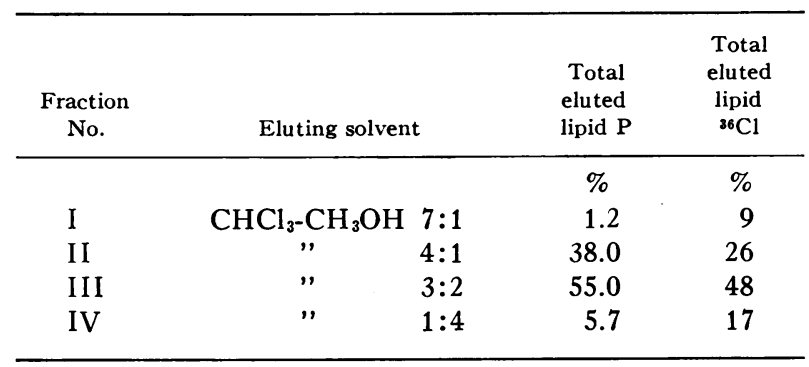

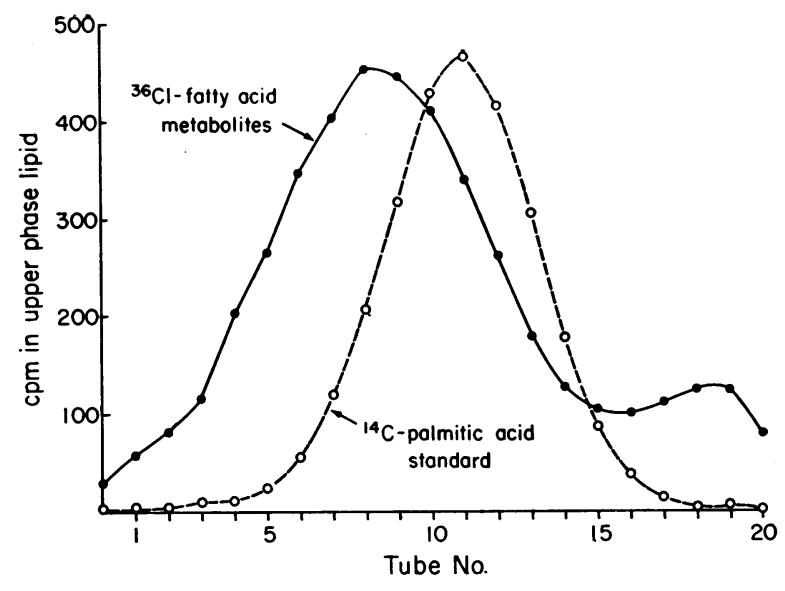

FIGLKE 1 Countercurrent distribution of ${ }^{38} \mathrm{Cl}$-fatty acid metabolites (in vivo labeling) together with added standard ${ }^{14} \mathrm{C}$-palmitic acid.

then $\left(A_{r+1} / A_{r}\right) /\left(B_{r+1} / B_{\mathbf{r}}\right)=K_{a} / K_{b}$. Since the right side is constant, so must be the left. Calculation from the data used to plot the curves in Figs. 1 and 2 shows that this ratio varies with successive pairs of adjacent tubes. The chlorinated lipid is therefore heterogeneous.

Urea adduction. A portion of the methyl ester mixture containing ${ }^{38} \mathrm{Cl}$-esters and ${ }^{14} \mathrm{C}$-methyl palmitate was retained from the last 10 tubes of the countercurrent distribution. Solvents were evaporated and the esters dissolved in hot $15 \%$ urea in methanol. Urea adducts were allowed to precipitate overnight at $25^{\circ} \mathrm{C}$. Adducted esters in the precipitate and excluded esters in the supernatant were recovered. Table II shows the isotope ratio in the original mixture, in the adduct, and in the supernatant. The chlorinated metabolites are clearly mainly branched-chain lipids.

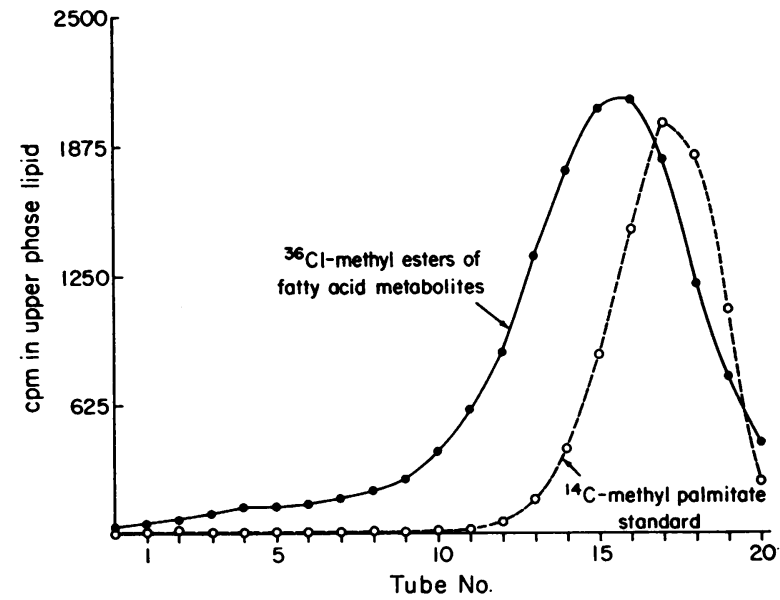

FIGURE 2 Countercurrent distribution of methyl esters of ${ }^{36} \mathrm{Cl}$-fatty acid metabolites (in vivo labeling) together with added standard methyl ${ }^{14} \mathrm{C}$-palmitate.

Lipid Metabolites of Carbon Tetrachloride 
TABLE II

Comparison of Urea Adduction of ${ }^{36} \mathrm{Cl}$-Fatty Acid Methyl Esters with ${ }^{14} \mathrm{C}$-Methyl Palmitate

\begin{tabular}{lrrc}
\hline \multicolumn{1}{c}{ Lipid mixture } & ${ }^{36} \mathrm{Cl}$ & ${ }^{14} \mathrm{C}$ & $\begin{array}{c}{ }^{36} \mathrm{Cl} /{ }^{14} \mathrm{C} \\
\text { ratio }\end{array}$ \\
\hline Starting mixture & $c p m$ & $c p m$ & \\
Precipitate (urea adduct) & 2730 & 1561 & 1.7 \\
Supernatant (excluded esters) & 610 & 1461 & .42 \\
& 2107 & 0 & $\infty$ \\
\hline
\end{tabular}

Acetone-soluble liver lipids were likewise hydrolyzed, then analyzed by countercurrent distribution and urea adduction. Again, the radioactivity was found incorporated into branched, long-chain fatty acids.

\section{Liver Lipids after the Injection of Doubly LABELED $\mathrm{CCl}_{4}$}

Fasted rats were injected with 0.5 or $1 \mathrm{ml}$ of Lipomul containing a mixture of ${ }^{14} \mathrm{C}$ - and ${ }^{30} \mathrm{Cl}$-carbon tetrachloride. At $15 \mathrm{~min}$, approximately $0.1 \%$ of the injected radioactivity was found incorporated in liver lipids. $68 \%$ of the lipid radioactivity was found in the acetoneprecipitable lipids. Fatty acid methyl esters were prepared from the acetone-precipitable lipid for countercurrent distribution.

Fig. 3 shows the countercurrent distribution of doubly labeled methyl esters. Above the distribution curve is a plot of the ${ }^{36} \mathrm{Cl} /{ }^{44} \mathrm{C}$ ratio in the lipid of each tube divided by the ratio in the injected dose, the quotient multiplied by four. It is seen that the predominant route to the labeled lipid involves the incorporation of three of the four chlorine atoms from each molecule of $\mathrm{CCl}_{4}$, but some lipid is formed using all the $\mathrm{CCl}_{4}$ chlorine atoms.

Formation of doubly labeled lipids by liver slices

Slices weighing $100-150 \mathrm{mg}$ were taken from livers of starved rats. Two slices per flask were incubated at

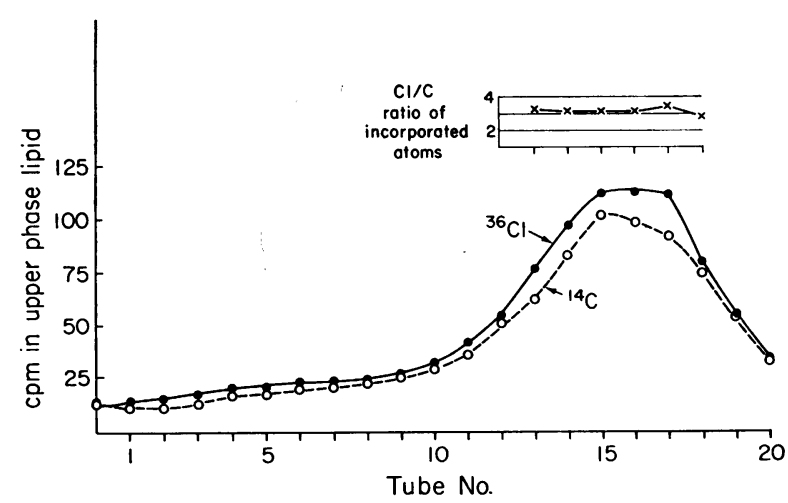

FIgURE 3 Countercurrent distribution of methyl esters of doubly labeled fatty acid metabolites (in vivo labeling).
TABLE III

Incorporation of ${ }^{36} \mathrm{Cl}$ Radioactivity into Lipid by Rat Liver Slices after Incubation in Radioactive $\mathrm{CCl}_{4}$

\begin{tabular}{|c|c|}
\hline Time & ${ }^{36} \mathrm{Cl}$ \\
\hline $\min$ & $c p m / m g$ wet tissue \\
\hline 5 & 158 \\
\hline 15 & 326 \\
\hline 30 & 480 \\
\hline 60 & 1114 \\
\hline 60 (control slices) & 46 \\
\hline 60 (control slices) & 44 \\
\hline
\end{tabular}

$37^{\circ} \mathrm{C}$ in $3.5 \mathrm{ml}$ Krebs-Ringer bicarbonate buffer to which $0.5 \mathrm{ml}$ Lipomul containing "doubly-labeled" $\mathrm{CCl}_{4}$ was added. Slices and buffer in two control flasks were heated $1 \mathrm{~min}$ in a water bath at $100^{\circ} \mathrm{C}$ before the Lipomul was added. Incubations were stopped after 5 , 15,30 , and $60 \mathrm{~min}$. Control flasks were incubated 60 min. After incubation, slices were removed with forceps, rinsed copiously with saline, and the lipids were extracted. Table III shows the increasing incorporation of radioactivity into slice lipids with time in the surviving slices. The extracts were then pooled, fatty acid methyl esters again prepared from the acetone-precipitable lipid, and distributed in the countercurrent system heptane-acetonitrile. Fig. 4 shows that the labeled lipids behave similarly to those obtained in vivo.

Free radical addition of carbon tetrachloride to methyl oleate

Methyl oleate $(250 \mathrm{mg})$, carbon tetrachloride $(3.5 \mathrm{ml})$ containing ${ }^{14} \mathrm{C}$ - and ${ }^{96} \mathrm{Cl}$-tracer, and dibenzoyl peroxide $(7 \mathrm{mg})$ were heated together under argon in a sealed ampoule $16 \mathrm{hr}$ at $85^{\circ} \mathrm{C}$. The ampoule was then heated 1 additional $\mathrm{hr}$ at $110^{\circ} \mathrm{C}$ to destroy the peroxide. After cooling, the reaction mixture was washed first with $10 \%$

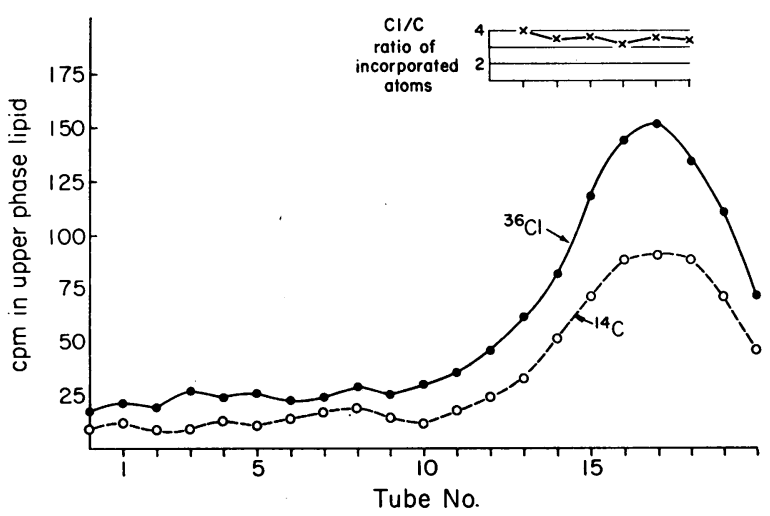

FIGURE 4 Countercurrent distribution of methyl esters of doubly labeled fatty acid metabolites (in vitro labeling). 


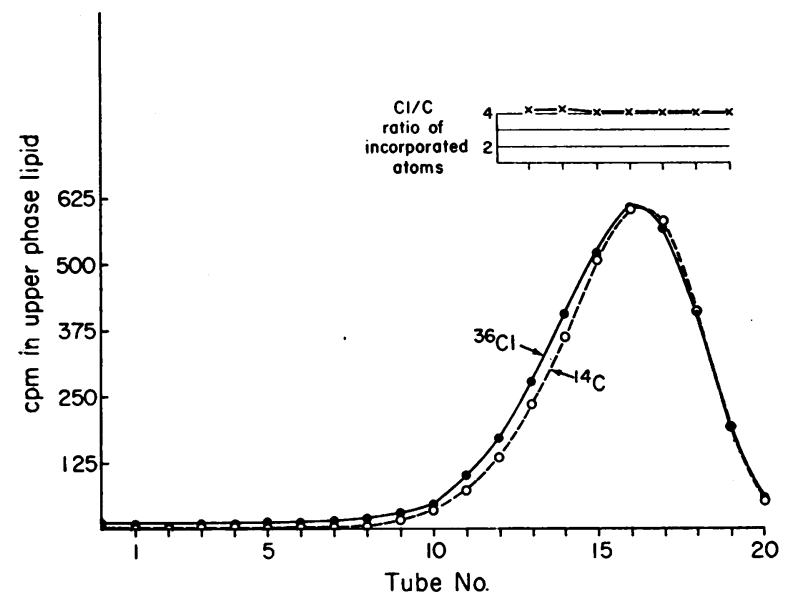

FIGURE 5 Countercurrent distribution of products of peroxide-catalyzed addition of doubly labeled carbon tetrachloride to methyl oleate. Solvent system: heptane-acetonitrile, $10 \mathrm{ml}$ upper phase, $10 \mathrm{ml}$ lower phase.

$\mathrm{NaHCO}_{3}$, then with water. The solvent was evaporated and the residue dissolved in petroleum ether (bp $60^{\circ}-$ $70^{\circ} \mathrm{C}$ ). The solvent was re-evaporated, and the lipid radioactivity assayed. Approximately $3 \%$ of the radioactivity was incorporated into lipid.

A portion of the lipid residue was analyzed by countercurrent distribution. Fig. 5 shows the results. The radioactive lipid behaves as long-chain ester. Under the conditions of this reaction (excess carbon tetrachloride), most of the product is seen to contain all four of the $\mathrm{CCl}_{4}$ chlorine atoms.

Another portion of the lipid in the final reaction mixture was dissolved in hot $15 \%$ urea in methanol, and the adducts were allowed to form overnight at $25^{\circ} \mathrm{C}$. Samples of the original methyl oleate, of the lipids in the ampoule at the end of the reaction, of the adducted esters, and of the excluded esters were analyzed by thin-layer chromatography on $\mathrm{AgNO}_{3}-$ silicic acid. The results (Fig. 6) demonstrated that a saturated product was produced, and that this product was branched. On a second $\mathrm{AgNO}_{5}$-silicic acid plate, about $50 \mathrm{mg}$ of the final reaction mixture was applied to the origin as a band, and the chromatography repeated. Bands corresponding to the saturated esters and the monoenes were scraped from the plate with a razor blade, and the esters eluted

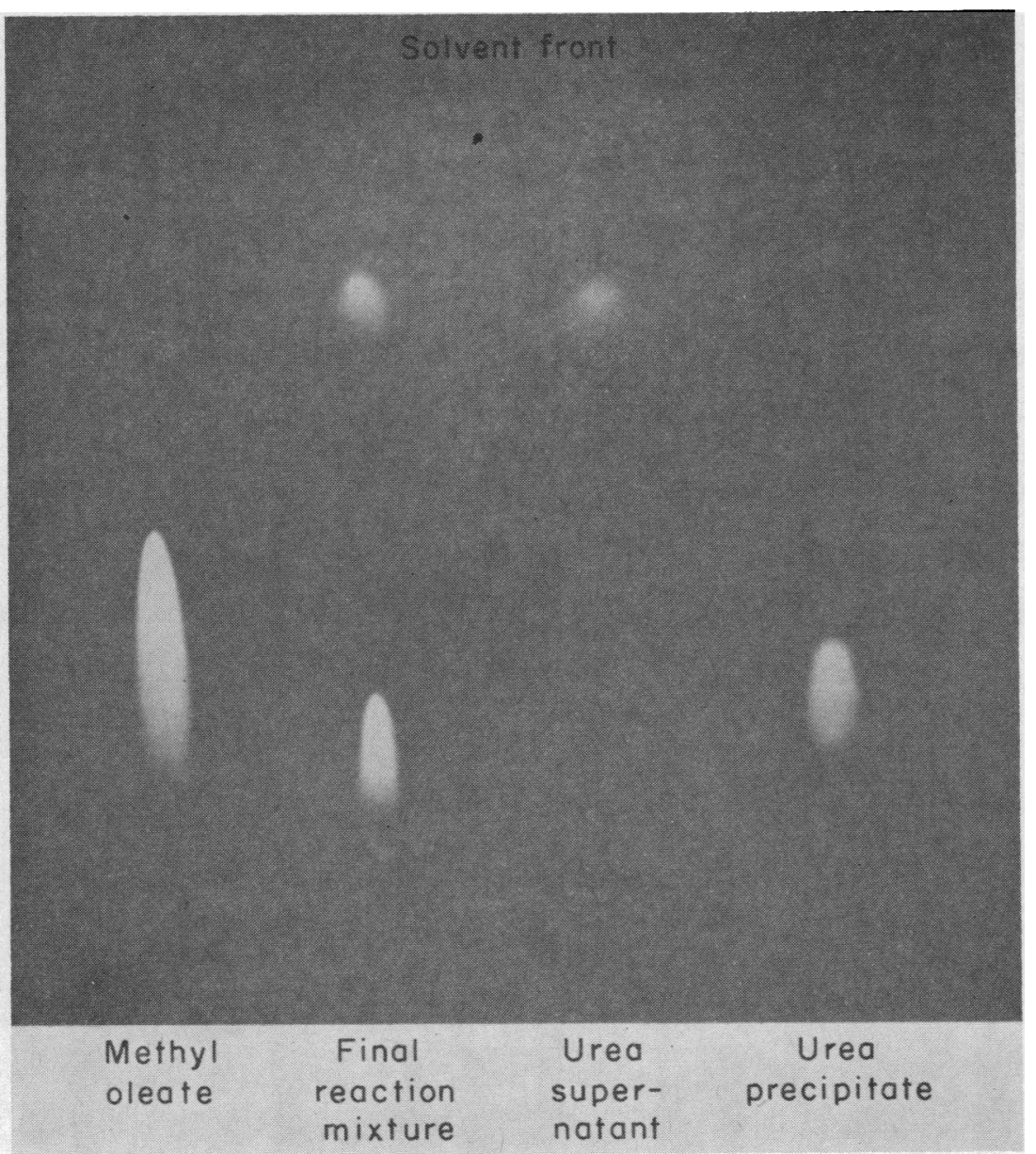

FIGURE 6 Analysis of peroxide-catalyzed addition of labeled $\mathrm{CCl}_{4}$ to methyl oleate. Thin-layer chromatography on silver nitrate-impregnated Silicagel G. Solvent: reagent grade chloroform, used without further purification. Plate sprayed with dichlorofluorescein, photographed in uv light. Samples analyzed were methyl oleate, total lipid residue at the conclusion of the reaction, the lipids in the residue which did not form urea adducts, and those that did. The products of the reaction are seen to be saturated branched compounds. 
from the scrapings with ethyl ether. Radioactivities of both fractions were assayed. $97 \%$ of the radioactivity was found in the saturated esters.

\section{DISCUSSION}

These studies confirm Reynolds' observations that liver lipids are labeled both by ${ }^{14} \mathrm{C}$ - and ${ }^{36} \mathrm{Cl}$-carbon tetrachloride. More than half the labeling occurs in the phospholipid fraction. The studies reported here show that the new compounds are a heterogeneous group of branched long-chain fatty acids containing both carbon and chlorine. Surviving liver slices can also form these metabolites. In a simple chemical system which generates trichloromethyl free radicals, the addition of carbon tetrachloride to methyl oleate produced a saturated product which behaved like the metabolites during urea adduction and countercurrent distribution. The evidence suggests that the free radical mechanism is the route to the metabolites formed in vivo.

Any theory which relates the toxicity of carbon tetrachloride to its metabolism must satisfy at least two requirements: $(a)$ it must explain the decreasing order of toxicity of $\mathrm{CCl}_{4}$, chloroform, and $\mathrm{CCl}_{3} \mathrm{~F}$, and $(b)$ the metabolic transformation should occur at least as soon as the morphologic change and should help explain it. Of the three halomethanes, carbon tetrachloride forms free radicals most easily, $\mathrm{CCl}_{3} \mathrm{~F}$ least (21). The rapidity and locus of labeling of liver lipid is compatible with the rate of onset and locus of the morphological changes after ingestion of a toxic dose of $\mathrm{CCl}_{4}$. The first effect on the liver demonstrable by electron microscopy is the disruption and vesciculation of the cisternae of the coarse endoplasmic reticulum and the dispersion of ribosomal particles $(22,23)$. At this stage these ribosomes are severely incapacitated in protein-synthesizing ability (24). Presumably the disruption of the ordered structure of the endoplasmic reticulum could result from damage to its lipid membranes.

Recknagel has proposed that the $\mathrm{CCl}_{3} \cdot$ radicals initiate destructive chain peroxidation of unsaturated lipids (25). The active methylene bridges of dienes and polyene fatty acids are excellent targets for radical attack (13). Recknagel found that peroxides could not be directly identified in vivo, since their identification depends on determination of malonaldehyde, itself metabolized by liver. However, he was able to show increased diene conjugation after $\mathrm{CCl}_{4}$ administration, a reaction which accompanies lipid peroxidation. An alternative role for the radical reaction is the formation of chlorinated lipids, which may be unsuitable as membrane components. Cross-linking and polymerization of lipids containing unsaturated fatty acids might also result from free radical attack, along with peroxidation or chlorination. The protective effect of certain antioxidants against $\mathrm{CCl}_{4}$ poisoning $(1,2)$ is compatible with the radical mechanism, since these compounds can function as free radical inhibitors. Of course, evidence for a metabolic pathway is not proof that it is responsible for toxicity. The existence of the free radical mechanism seems well established. Whether any of its possible consequences account for the toxicity of $\mathrm{CCl}_{4}$ remains to be proven.

\section{ACKNOWLEDGMENTS}

I wish to thank Mrs. Giedre Stankunas for skilled technical assistance.

This work was supported by U. S. Public Health Service Grant AM 03963-08.

\section{REFERENCES}

1. Gallagher, C. H. 1961. Protection by antioxidants against lethal doses of carbon tetrachloride. Nature. 192: 881.

2. DiLuzio, N. R., and F. Costales. 1964. Inhibition of the carbon tetrachloride fatty liver by antioxidants. Fed. Proc. 23: 520. (Abstr.)

3. Plaa, G. L., E. A. Evans, and C. H. Hine. 1958. Relative hepatotoxicity of seven halogenated hydrocarbons. $J$. Pharmacol. Exp. Ther. 123: 224.

4. Slater, T. F. 1965. A note on the relative toxic activities of tetrachloromethane and trichloro-fluoro-methane on the rat. Biochem. Pharmacol. 14: 178.

5. Judah, J. D., and K. R. Rees. 1959. Mechanism of action of carbon tetrachloride. (Discussion, T. M. Brody.) Fed. Proc. 18: 1017.

6. Brody, T. M., D. N. Calvert, and A. F. Schneider. 1961. Alteration of 'carbon tetrachloride-induced pathologic changes in the rat by spinal transection, adrenalectomy, and adrenergic blocking agents. J. Pharmacol. Exp. Ther. $131: 341$.

7. Poggi, M., and R. Paoletti. 1964. A new insight on carbon tetrachloride effect on triglyceride transport. Biochem. Pharmacol. 13: 949.

8. Sigel, B., L. B. Baldia, M. R. Dunn, and M. E. Dimbiloglu. 1967. Carbon tetrachloride effect on liver autotransplants with totally reversed blood flow. Nature. 213: 1258 .

9. Recknagel, R. O. 1967. Carbon tetrachloride hepatotoxicity. Pharmacol. Rev. 19: 145.

10. McCollister, D. D., W. H. Beamer, G. J. Atchison, and H. C. Spencer. 1951. The absorption, distribution, and elimination of radioactive carbon tetrachloride by monkeys upon exposure to low vapor concentrations. $J$. Pharmacol. Exp. Ther. 102: 112.

11. Butler, T. C. 1961. Reduction of carbon tetrachloride in vivo and reduction of carbon tetrachloride and chloroform in vitro by tissues and tissue constituents. J. Pharmacol. Exp. Ther. 134: 311.

12. Walling, C. 1957. Free radicals in solution. John Wiley \& Sons, Inc., New York.

13. Holman, R. T. 1954. Autoxidation of fats and related substances. In Progress in the Chemistry of Fats and other Lipids. R. T. Holman, W. O. Lundberg, and T. Malkin, editors. Macmillan and Company, N. Y.

14. Reynolds, E. S. 1967. Liver parenchymal cell injury. IV. Pattern of incorporation of carbon and chlorine from carbon tetrachloride into chemical constituents of liver in vivo. J. Pharmacol. Exp. Ther. 155: 117.

15. Hanahan, D. J., J. C. Dittmer, and E. Warashina. 1957. A column chromatographic separation of classes of phospholipides. J. Biol. Chem. 228: 685. 
16. Sunderman, F. W., and F. W. Sunderman, Jr. 1960. Lipids and the steroid hormones in clinical medicine. J. B. Lippincott Co., Philadelphia.

17. Ahrens, E. H., Jr., and L. C. Craig. 1952. Separation of the higher fatty acids. J. Biol. Chem. 195: 299.

18. Schlenk, H. 1954. Urea inclusion compounds of fatty acids. In Progress in the Chemistry of Fats and Other Lipids. R. T. Holman, W. O. Lundberg, and T. Malkin, editors. Macmillan and Company, New York.

19. Baròn, M. 1961. Analytical applications of inclusion compounds. In Physical Methods in Chemical Analysis. W. G. Berl, editor. Academic Press Inc., New York.

20. Kaufmann, H. P., and H. Wessels. 1964. Die Dünnschicht-Chromatographie auf dem Fettgebiet. XIV: Die Trennung der Triglyceride durch Kombination der Ad- sorptions- und der Umkehr-phasen Chromatographie. Fette Seifen Anstrichm. 66: 81.

21. Gregory, N. L. 1966. Carbon tetrachloride toxicity and electron capture. Nature. 212: 1460.

22. Smuckler, E. A., O. A. Iseri, and E. P. Benditt. 1962. An intracellular defect in protein synthesis induced by carbon tetrachloride. J. Exp. Med. 116: 55.

23. Reynolds, E. S. 1964. Liver parenchymal cell injury. I. Initial alterations of the cell following poisoning with carbon tetrachloride. J. Cell Biol. 19: 139.

24. Smuckler, E. A., and E. P. Benditt. 1965. Studies on carbon tetrachloride intoxication. III. A subcellular defect in protein synthesis. Biochemistry. 4: 671.

25. Recknagel, R. O., and A. K. Ghoshal. 1966. Lipoperoxidation as a vector in carbon tetrachloride hepatotoxicity. Lab. Invest. 15: 132. 